\title{
Anatomy of Persuasive Discourse (on some functional and semantic aspects of literary discourse analysis) ${ }^{1}$
}

\author{
Tigran Mikayelyan \\ Khachatur Abovian Armenian State Pedagogical University
}

\begin{abstract}
The problem of persuasive discourse has been analyzed in this article from the perspectives of literary discourse - to be specifically chosen and introduced - much more as a model of communicative behaviour and pattern of textuality rather than as a sample of artistic perception of life. The survey into the structure of persuasive discourse suggested by María Azucena Penas Ibáñez has served as basis for the paper that tries to cover the major constituents of a relatively overall image of persuasive discourse completed under all the standards of textuality. The paper attempts at introducing a paradigm of factors to be taken into consideration in respective analyses of persuasive discourse.
\end{abstract}

Key words: persuasive discourse, discursive functions, personal (sub)goals, textuality, deictic egocentrism.

\section{Introduction}

"To be persuasive we must be believable; to be believable we must be credible; to be credible we must be truthful"

(Edward R. Murrow)

The anatomy of persuasive discourse has been highlighted within different contexts ranging from the philosophical eloquence to literary creativity messages. The major issues detected so far stem particularly from purposeful speech act and effective communication in particular. The major findings in the domain have been detected in the realms of major standards of text as a process, otherwise - textuality. As the American journalist claims, the persuasiveness is a matter of a whole chain of requirements that one should be aware of in order to be persuasive in her/his statements, claims, deeds and conclusions. Edward Murrow suggests persuasiveness as an outcome arising from believability, credibility and truthfulness - profoundly ethical values for the society and more than professionally required confessions for a journalist. 
However, the anatomy of persuasive discourse might be multi-fold, and is likely to cover all the possible mechanisms of discursive attainment - from the outer impression to a deeply hidden message. The persuasion might be observed, like any other targetoriented discourse, both as a "process" and as a "product". The PR techniques, indeed, among other prerequisites, assume also believability-reliability seeking for the truth, however, every single step towards the truth, which might actually vary from $a$ truth to $a$ truth - dependent on the purpose and/or final goal of the discourse. The persuasive discourse, as a process, goes through a number of stepwise strategies of argumentation, statement, evidencing, claiming, evaluating, witnessing, etc. As a product or discursive output, the same discourse is likely to result in propaganda, campaigns, preaching, assessment, etc. Every single step that is meant or insinuated in the course of such discourse ends up as a specific outcome which is easy to recognize. Moreover, it comprises the prioritization of the process or, on the contrary, of the outputs in consequent swap of real discursive roles, i.e. process $\rightarrow$ product, product $\rightarrow$ process.

\begin{tabular}{|l|l|}
\hline Process (Output) & Output (Process) \\
\hline Specification & Argumentation \\
\hline Speculation & Narration \\
\hline Evaluation & Discrimination \\
\hline Statement & Rejection \\
\hline Claim & Disclaim \\
\hline Advocacy & Objection \\
\hline
\end{tabular}

We state the obvious claiming that some of the concepts paired in opposed dichotomy above are absolutely contradictory, whereas, some of them are introduced as mutually completing. Therefore, we may claim that the opposition introduced in the table above may unfold in two main directions: as mutually exclusive and mutually completing. It goes without saying that the list could be enriched and even changed completely - in line for relevant order of items involved.

\section{Persuasive Discourse: Functional Perspective.}

If we go deeper into these processes, we determine that the major functions, accomplished in the course of these processes, could be confined to three major framework functions: definition, classification, and generalization. These three functions make up a kind of basic triangle building up the fundamental cells of persuasive discourse, however, not necessarily in the very order stated above. Graph 1 below is a rough illustration of the functions depicted from Speaker's perspective. 


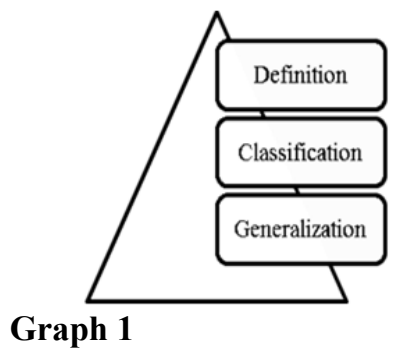

These functions show vividly the realignment from the preciseness of the statement, its subjective attainment aimed at objectivity, perceptibility or acceptability. Moreover, the communication flow goes right through the possible concept-based and/or statement-based grouping which makes the objectivization of the given statement much more stepwise and smoother for a listener, eventually, providing the necessary degree of acceptability - from Listener's point of view, or persuasive effect - from Speaker's perspective.

As for the anatomy of persuasive discourse and the major trends in communicative strategy, one of the hurdles that we are likely to face in the analysis is the problem of the content of persuasion, namely, the semantic structure of argumentative discourse aimed at prompt persuasion. From this perspective, we reckon it necessary to quote the conclusions at which Spanish scholar María Azucena Penas Ibáñez has arrived in her article "From Conceptual Meaning to Intentional Meaning in Argumentative Persuasion: A Literary Case": "In any case, it is clear that the discursive exchanges that construct a text have to be understood as general strategic actions with the purpose of reconducting and directing any sort of situation in which human beings interact with each other in such a way that we can conclude that, through the manipulation of expectations and the controlled sequencing of information, [the participants of communication $^{2}$ are able to put forward their proposals orienting them towards the achievement of their goals and subgoals, in an extremely persuasive way"3 (Penas Ibáñez 2011:131).

Thus, Professor Penas Ibáñez asserts reconducting and directing as strategic moves of foremost importance in communicative intercourse, observing them as functionally prioritized in the control over information flow. Therefore, we may deduce that, even in spontaneous communicative intercourse, persuasion might be patterned and, in fact, structured through the linguistically marked intentions that stem from a variety of personal goals and subgoals. It should be noted that the excerpt analysed by the Spanish scholar might be considered as a relevant and typical model of a spontaneous communicative act "dressed" in a creative literary context.

The exploration into peculiarities and strategic moves within persuasive discourse is of particular significance from both theoretical and practical standpoints: it may 
contribute to the mechanisms of discourse analysis revealing the techniques of critical thinking through the written discourse. It might also be applied to attain the objectives of reading between the lines and deeper analytical reading/listening. The ethical aspect of such surveys is obvious as well, and it helps to avoid the possible imposition of absolutely subjective ideas, statements and/or claims.

\section{Persuasive Discourse: Methodological References.}

The methodology of analysis applied by Professor Penas Ibáñez is, quite justly, of ostensive-inferential character with the inevitable cooperation and relevance principle as an absolute background (Penas Ibáñez 2011:113). Together with the precise choice of perspective and methodology, so relevant for critical discourse analysis, the researcher commences the paper with the precise definition of the argumentative persuasion as a process facilitated and maintained as gradual negotiation sequences (Penas Ibáñez 2011:113). The methodology provides the necessary degree of comprehension and illustrative explicitness and transparency in observations. The standpoint is crucial for differentiating the general nature of the process (as a negotiation), role-switching (as a criterion of participation or involvement) and gradual procedure (as a stepwise proceeding). These aspects are equally contributing to the major principle of bilateralism (or multilateralism) in human communication and the input of personal (subjective) intention into the contextualized (objective) intercourse. Moreover, the contextualization may also be scrutinized - in a deeper and more relevant way - from this perspective. Thus, on the one hand, as stated by the researcher, the contextualized objective domain of communication embraces all the possible needs, intentions of participants, meanwhile, on the other hand, it requires a specific strategy adjustment that, due to the same participants, goes through an adjustment process which adds up even more agile dynamism to communication (Penas Ibáñez 2011:114). Thus, at every single step, the participants face subjective needs and objective intentions to be verbalized through specific communication strategies. With special reference to other scholars (Fuentes and Alcaide), the researcher makes the investigation even more clearcut, emphasizing the difference between persuasion and manipulation. The pertinent paragraph on subject matter reads: "If persuasion is the ultimate goal of most of our argumentative acts, as it is not possible not to argue (Simonet \& Simonet, 1990:49), manipulation is not seen as an effect, at least not a legitimate one, of the argumentative act. This emerges directly from the violation of one of the most valued cooperative principles of discourse, quality, which refers to the sincerity of our discursive interventions.” (Penas Ibáñez 2011:115).

\section{Persuasion vs. Manipulation}

If, for a while, we disregard the problem of truthfulness stated by the scholar, as well as many other specialists of discourse analysis, the inner engine of argumentative discourse, though quite cynically, might open up a curious image of two, absolutely 
opposing vectors of persuasion vs. manipulation ${ }^{4}$. If this opposition is set against the simplest communicative pattern (Speaker (Writer) - Listener (Reader)), where the participants are perceived as equally important, involved and influential, we may observe some new members in the opposition which derive from bilaterally active and general communicative intentions of the participants of any speech act. The paradigm might be enriched in the following way: persuasion - (quasi-persuasion) vs. (quasimanipulation) - manipulation. Apparently, the quasi-persuasion seems to be the most frequent communicative strategy. It comprises the highest degree of speaker's intention, more precisely, his/her persistence of destructive character. As a matter of fact, this strategy is marked with stylistic markers expressing irony, tautology, demagogy, etc. The quasi- manipulation, as we might have noticed, is likely to emerge in cases when the Recipient allows, accepts and/or considers convenient to accept what is conveyed by the Speaker as persuasive, convincing and/or true. This happens quite frequently in cases of humour, absolute authority or ultimate confidence highlighted. Thus, the quasipersuasion is observed within the Speaker's radius of communication intercourse, while the quasi-manipulation is a phenomenon observed within the Listener's ambit. Respectively, under the principle of reciprocity, quasi-persuasion is a vector directed against the Speaker, resulting in self-persuasion, while quasi-manipulation is a vector aimed against the Listener, ending up in self-manipulation.

The more-or-less complete formula might look like this:

$$
\begin{aligned}
& \text { SPEAKER (self-persuasion) } \leftarrow \text { persuasion } \leftarrow \text { (quasi-persuasion) } \\
& \rightarrow \leftarrow \\
& \text { (quasi-manipulation) } \rightarrow \text { manipulation } \rightarrow \text { (self-manipulation) LISTENER }
\end{aligned}
$$

More specifically patterned, we would state:

(1) I persuade (persuasion) vs. I think I persuade (self-persuasion).

(2) I am manipulated (manipulate) vs. I allow to be manipulated (self-manipulation).

Certainly, the degrees and depths of the strategies operated might vary from case to case. Besides, what we have stated as the most typical contexts for quasi-persuasion and quasi-manipulation, needs a deeper survey into the nature of communication, and overall intercourse between its participants. All again, the subjective (interiorized) input into the objective (exteriorized) context might be of decisive importance for further scrutiny. This is what Professor Penas Ibáñez also emphasizes in her article, in particular, speaking about the variety of constituents present in persuasive discourse (not only reasoning but also emotions, personal experience, etc.), and the actual priority of context of socialization (Penas Ibáñez 2011:116-117). The constituents of persuasive discourse cannot but be observed within the context of implicit assumptions which shape up the course of communication and persist as a major factor of understanding. The same scholar refers to such assumptions emphasizing that "when we reconstruct them, speaker's reasoning has to operate in an inferential way by using hypothesis, until he or she finds the most relevant one" (Penas Ibáñez 2011:118). Subsequently, every single step in persuasive discourse is a set of double-directed communicative initiatives 
which might result in effective $e^{5}$ persuasion or might be a complete failure. Thus, the realistic productiveness of persuasion is observed when both parties involved coincide in major operations set forth as an absolute priority or precise objective of the given communicative act. Any of the functions might be of absolute priority, and the contextually motivated factors, might vary due to situations, participants and contexts.

In Graph 2 below we can see the process of persuasion or effective persuasive communication symbolized from the standpoints of both participants: the Speaker and the Listener. In fact, the rotated triangles echo the triangle of Graph 1, with only one exception: we have not stated the underlying situationally motivated communicative functions.

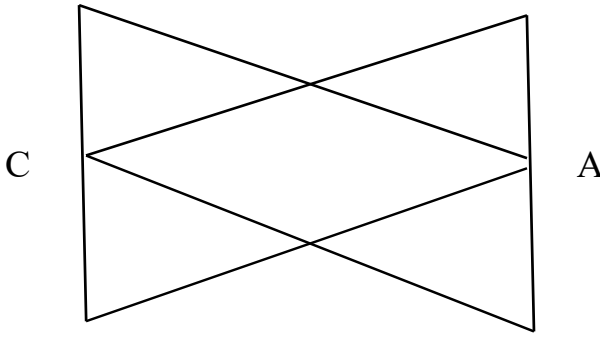

\section{Graph 2}

Thus, the overlapping areas are the areas of persuasive discourse. Consequently, persuasion is considered as successful if the point of argument (angle A) is in line with the point of convincement (angle C), i.e. an agreement of bilateral projection. Certainly, the process outlined is particularly generic and does not involve all the details of respective mechanisms of persuasive discourse. However, it traces the mechanistic, but somehow dynamic nature of persuasion at least from the most productive perspective of its realization. Moreover, Graph 2 does not seem quite exhaustive from the standpoint of the dynamics of deliberate communicative modelling of situation, stated in Professor María Azucena Penas Ibáñez's paper as: reconducting and directing the communicative situation (Penas Ibáñez 2011:120). These two operations, so abstractedly separable, illustrate a much more complicated picture of the state of play. Besides, the graph does not provide a relevant depiction of a failure in persuasive discourse, i.e. the possible instances of incomplete, filed or inconsistent discursive persuasion. The Spanish scholar, while analyzing persuasion within literary discourse, enumerates some of the instances which might risk the effectiveness of persuasive discourse or are likely to result in its complete failure: (a) explicit rejection, (b) questioning, (c) ignoring, and (d) subjective interest based focusing (Penas Ibáñez 2011:121).

Thus, it becomes obvious that the objective illustration of possible subjective influence on communication is beyond any general or overall description, however, one of the major realms where proper investigations are more than crucial is the realm of 
subjective operations and subjective influence on communication. This influence, as stated by the same Spanish scholar, might be of both subjective and objective characters, finding its way out through both linguistic and extra-linguistic and/or paralinguistic resources. The spontaneous combination of all the communicative resources might get canalized through a wide range of communicative acts found in the paradigm of contextual clues: illustrations drawing direct attention (explicit evoking), exemplification with actual reference to the procedure which might be both the object and subject of observation and communication (actual reference to the reality), involvement with special reference to subjective, personal experience of both cognitive and emotional character (experience-based reference to the reality) (Penas Ibáñez 2011:121).

British philosopher John Locke, in his "An Essay Concerning Human Understanding", separates the primary and secondary qualities of the material world. He claims that the secondary qualities are subjective, like the colours, smells or tastes that are the effects left on human senses by real objects. In fact, these qualities cannot be found in real things and objects though the latter suggest and really are the reason for these qualities. Certain parallelism between Locke's concept of secondary qualities and persuasive discourse characteristics might be observed as they, in their actual effect, bear certain resemblance to the sensory perception of the objective world, and not the actual truthfulness of a statement or the fairness of conclusions and/or assumptions. Therefore, the persuasive discourse is a discourse of deictic egocentrism ${ }^{7}$ expressed through specific communicative strategies and reflected likewise.

\section{Conclusion}

The persuasive discourse can be submitted to effective analyses within both text as a product and text as a process. For literary discourse analysis, the persuasive discourse markers can be revealed within the situation / context modelled through contextual clues and communicative strategy markers highlighted by the Spanish scholar María Azucena Penas Ibáñez. As for structural insights, the constituent of textuality, including the spontaneous ones, the processes of reconducting and directing the communicative situation, so relevantly brought to light by the Spanish Researcher, must be observed not only stepwise (in accordance with communicative strategies applied with all the respective goals and subgoals) but also from interactive perspective, namely, observing the issues of possibly overlapping objectives: persuasion and manipulation.

\section{Notes:}

1. The paper is based on María Azucena Penas Ibáñez's research (Penas Ibáñez 2011:113-134).

2. The article quoted is dedicated to the problems of argumentative persuasion within literary discourse, and the major statements are based and/or illustrated through an 
extract from the novel "The Adventures of Tom Sawyer" by Mark Twain. Therefore, the exact reference to the protagonists is substituted within square brackets by terms of more general reference which we consider more relevant to this article.

3. Note that all the highlighted parts and terms are stated as in the original text.

4. The concept of discursive manipulation finds its exhaustive definition in Teun A. van Dijk's article "Discourse and Manipulation": "As suggested, manipulation as intended here is a communicative and interactional practice, in which a manipulator exercises control over other people, usually against their will or against their best interests. In everyday usage, the concept of manipulation has negative associations manipulation is bad - because such a practice violates social norms. It should therefore be borne in mind in the rest of this article that 'manipulation' is a typical observer's category, e.g. of critical analysts, and not necessarily a participant category; few language users would call their own discourse 'manipulative'." (Teun A. van Dijk 2006: 359-383, p. 360)

5. The word 'effective' does not assume the concept of truthfulness and/or fairness. This paper is a perspective of more function-based and operation-based constituents irrespective of some particularly significant fact-backed and/or ethical issues. As stated by T. Van Dijk, "Obviously, the boundary between (illegitimate) manipulation and (legitimate) persuasion is fuzzy, and context dependent: some recipients may be manipulated by a message that is unable to manipulate others. Also the same recipients may be more or less manipulable in different circumstances, states of mind, and so on.” (T. Van Dijk: 359-383, p. 360)

6. The original text retrieved from http://oll.libertyfund.org/titles/761

7. The concept inspired by Professor Yerznkyan, (Ерзинкян 2013:59-74)

\section{References:}

1. Locke, J. (1689) The Works of John Locke. / An Essay concerning Human Understanding, Part 1, Vol.1. Available at: <http://oll.libertyfund.org/titles/761> [Accessed July 2015].

2. Penas Ibáñez, M.A. (2011) From Conceptual Meaning to Intentional Meaning in Argumentative Persuasion: A Literary Case. // Problemata Literaria 69, Colección dirigida por Eva Reichenberger, en colaboración con Rosa Ribas, Kassel, Edition Reichenberger.

3. van Dijk, T.A. (2006) Discourse and Manipulation. // Discourse \& Society. Vol.17(2). SAGE Publications,

4. Yerznkyan, Ye.L. (2013) Deiksis slova, semantika i pragmatika. Yerevan: YSU. 


\section{Thpuntuqhy hununıjph uGuunnứuma}

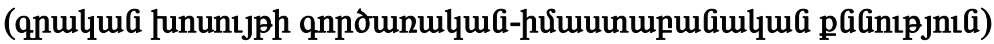

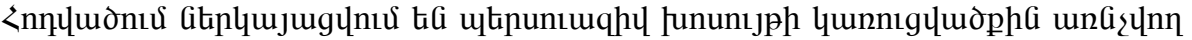

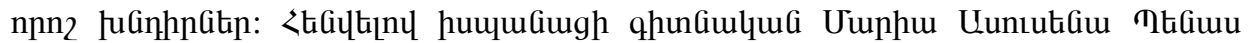

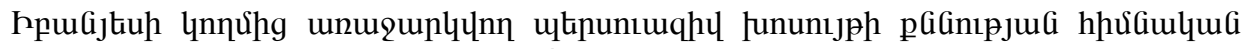

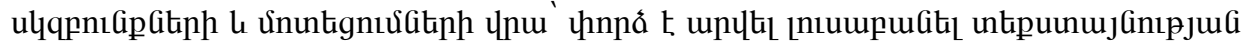

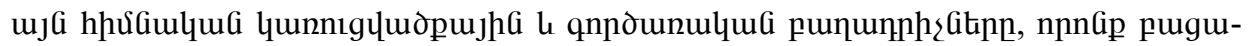

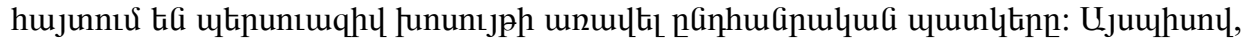

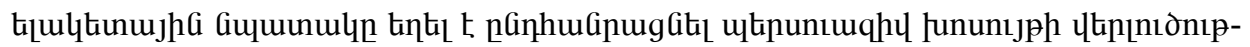

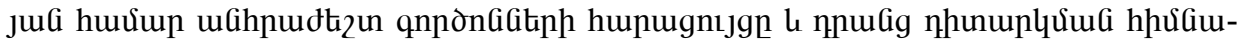

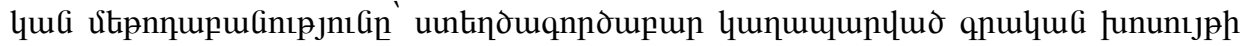
2nquGiulfitinnuर:

\section{Анатомия персуазивного дискурса \\ (функционально-семантический анализ литературного дискурса)}

В статье обсуждается проблема персуазивного дискурса с точки зрения литературного дискурса, которую специально выделили и представили больше как модель коммуникативного поведения и образец текстуальности, нежели как пример художественного восприятия жизни. Основываясь на исследовании структуры персуазивного дискурса, предложенного испанским профессором Марией Асусеной Пенас Ибаньесом, данная статья освещает основные элементы, которые воссоздают достаточно общую картину, учитывая все стандарты текстуальности. В статье представлена попытка обобщения парадигм факторов, которые должны учитываться в соответствующем анализе персуазивного дискурса. 